\title{
A Decade of Value Engineering in Construction Projects
}

\author{
Wei Tong Chen $\left(\mathbb{D},{ }^{1}\right.$ Hew Cameron Merrett $\mathbb{D}^{2},{ }^{2}$ Shu-Shun Liu, ${ }^{1}$ Nida Fauzia $\left(\mathbb{D},{ }^{1}\right.$ \\ and Ferdinan Nikson Liem $\mathbb{( 1 )}^{2,3}$ \\ ${ }^{1}$ Department of Civil and Construction Engineering, National Yunlin University of Science and Technology, Douliu, Taiwan \\ ${ }^{2}$ Graduate School of Engineering Science and Technology, National Yunlin University of Science and Technology, Douliu, Taiwan \\ ${ }^{3}$ Department of Civil Engineering, State Polytechnic of Kupang, Kupang, Indonesia
}

Correspondence should be addressed to Wei Tong Chen; chenwt@yuntech.edu.tw

Received 25 September 2021; Revised 9 January 2022; Accepted 7 February 2022; Published 7 March 2022

Academic Editor: Jorge Branco

Copyright (c) 2022 Wei Tong Chen et al. This is an open access article distributed under the Creative Commons Attribution License, which permits unrestricted use, distribution, and reproduction in any medium, provided the original work is properly cited.

\begin{abstract}
Over the past half-century, value engineering (VE) has emerged as an effective tool to manage time, costs, and quality with an aim to maximize value. It has been shown to be a highly effective approach for evaluating current construction projects. However, this tool's application in the construction domain is quite variable. This research aims to provide an in-depth quantitative and qualitative content analysis of the application of VE in construction projects. It is found that new research over the past decade has continuously improved the efficiency and productiveness of VE practices. Current work focuses on integrating VE with other disciplines, applying VE in diverse project domains, assessing VE performance, and developing new VE technologies. This broad review highlights some of the key areas of interest that required future investigation to ensure the continued delivery of value in the ever-changing and evolving construction industry.
\end{abstract}

\section{Introduction}

The construction industry faces unique commercial and operational challenges [1]. Construction projects routinely experience evolving expectations for project delivery and growing complexity, requiring construction companies to identify the optimal value approach for project delivery. Value engineering (VE) is increasingly being used in the construction industry to deliver value in a timely manner. Civil infrastructure projects have used VE for over half a century to drive value $[2,3]$. While the fundamentals of VE have remained largely unchanged, there have been advancements to maximize the benefits of the methodology and applications that extend beyond project cost.

In the construction field, VE application principally focuses on achieving the required project outcomes with the lowest overall project life cycle cost. As the construction industry evolves to deliver more value for money and meet increasingly complex delivery requirements, VE has an important role to play in meeting stakeholder value expectations. Typically, firms seek to deliver the function with the lowest overall project life cycle cost, exploring the use of alternative materials, design innovations, process reorganization to optimize efficiency, adapting transformative construction methods, optimizing time and costs, increasing quality, improving safety, and minimizing environmental impacts [4]. However, the perception of value ultimately hinges upon the criteria set for the delivery of each particular project.

Changes in the construction industry have increased the importance of VE in achieving value in the delivery of a wide range of projects. International construction projects tend to be more complicated than their domestic counterparts, and VE applications in such endeavours are still in the development stage [5]. While VE has an established role in the construction industry, VE applications in the construction domain need to continuously evolve to meet the changing needs of the industry. Furthermore, in many countries, good VE practices are still relatively limited in the construction industry [6]. Given the VE value proposition, this research 
reviews research on VE published between 2007 and 2021, seeking to provide a clear picture of VE applications in the construction domain with an eye to developing helpful insights into the development of best practices and to identify research gaps that need to be addressed.

\section{Principles of Value Engineering}

According to the SAVE International (2007), VE is a systematic process of job execution monitoring conducted by a multidisciplinary team to raise the project value by conducting an in-depth analysis of the relationship between project functions and costs. Al-Yousefi and Hayden also defined VE as a methodology in which changes are comprehensively considered to prevent unintentional changes. VE is unique among value management measures in that the objective is to drive the value through manipulating the function and cost (Value=Function/Cost). Typically, an increase in value is achieved by reducing costs, while meeting or enhancing the required project functions [7]. The desired outcome is that the project function is enhanced to improve the overall construction outcome value. VE can be applied to almost any product or project [8]. As such, VE is more than a simple cost-cutting measure.

VE differs from similar methodologies, such as costcutting, constructability, and reengineering in that VE entails a systemic procedure and implements a systematic VE job plan to enhance project value [9]. VE is best conducted by a multidisciplinary team of professionals and various subject matter experts. The Society of Japanese Value Engineering (SJVE) notes that VE is function-oriented and can be effectively used for service, product, system, or facility design projects. Therefore, the defining characteristics of VE are as follows: (1) the VE job plan (or 6-phase workshop) is supported by a team of professional experts; (2) it is function oriented; (3) it improves values; (4) it is cost effective. All these components are required in successful VE implementation [10-12].

A VE assessment entails three main stages: (1) a preworkshop stage, beginning with the discussion of how the workshop will be conducted and giving time for the workshop participants to prepare and gather the required information; (2) a workshop stage to develop a VE job plan where the VE participants jointly analyse project challenges and requirements and produce solutions; and (3) a postworkshop stage, which implements the outcome from the workshop phase and evaluates project performance.

The workshop stage provides a discussion forum to elucidate any uncertainties and ensure informed consensus among stakeholders [13]. Shown in Figure 1, the VE job plan is divided into six phases $[3,14]$ : information, function analysis, creativity, evaluation, development, and presentation. The information phase ensures a clear understanding of current project status and limitations and requires VE participants to acknowledge the owner's requirements and project constraints. Function analysis is the most critical and important step in VE, seeking to understand the project from a functional standpoint and to identify functions with high potential for

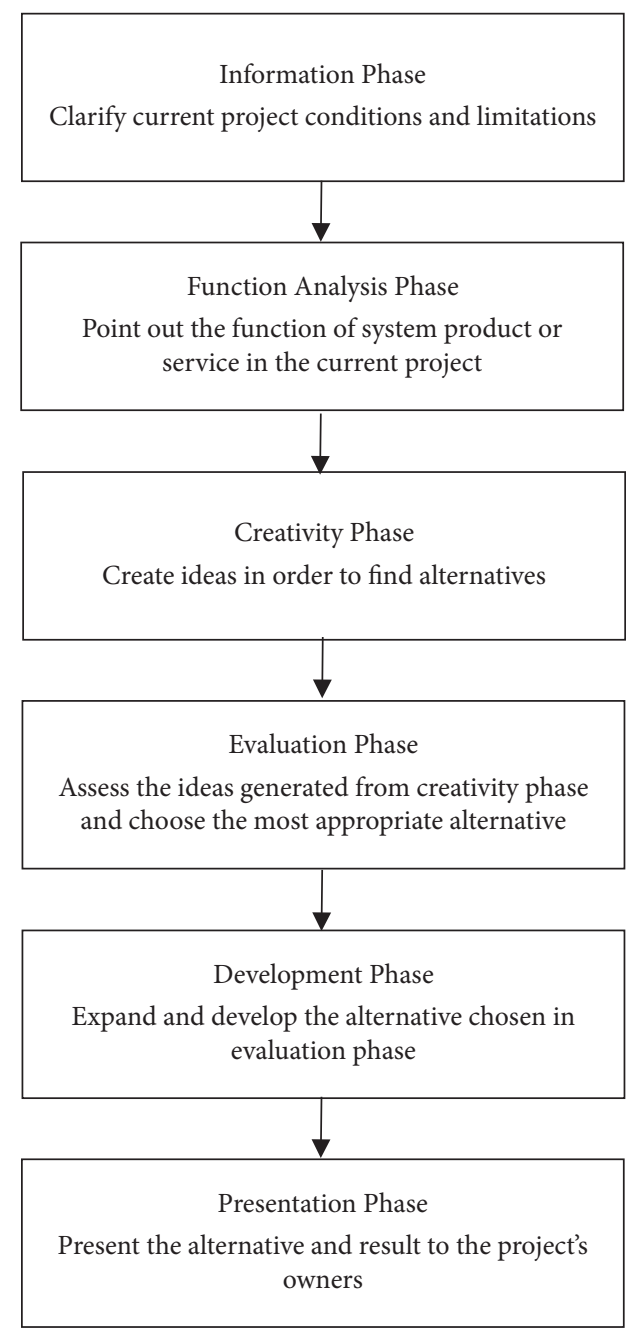

FIgURE 1: The VE workshop phases/VE job plan steps.

value improvement. The creativity phase generates ideas for alternative approaches to achieve the desired function. In the evaluation phase, these ideas are evaluated, and the most appropriate alternative will be chosen. The development phase analyses and further develops the chosen alternative to improve project outcomes. Finally, in the presentation phase, the alternative value proposition is delivered to the project owners, stakeholders, and decision-makers.

\section{Research Methodology}

This research conducts an in-depth narrative review of the existing literature concerned specifically with VE applications in construction projects to understand contemporary research and operational trends. Thematic data were examined by systematic identification and classification of patterns or themes [15], and content analysis is utilized to produce valid conclusions established by the collected data to represent and quantify specific occurrences. The content analysis approach provides advantages in that it is flexible, transparent, unobstructive, and applicable for various types of information [16]. As shown in Figure 2, content analysis is considered as the most appropriate method for this research 


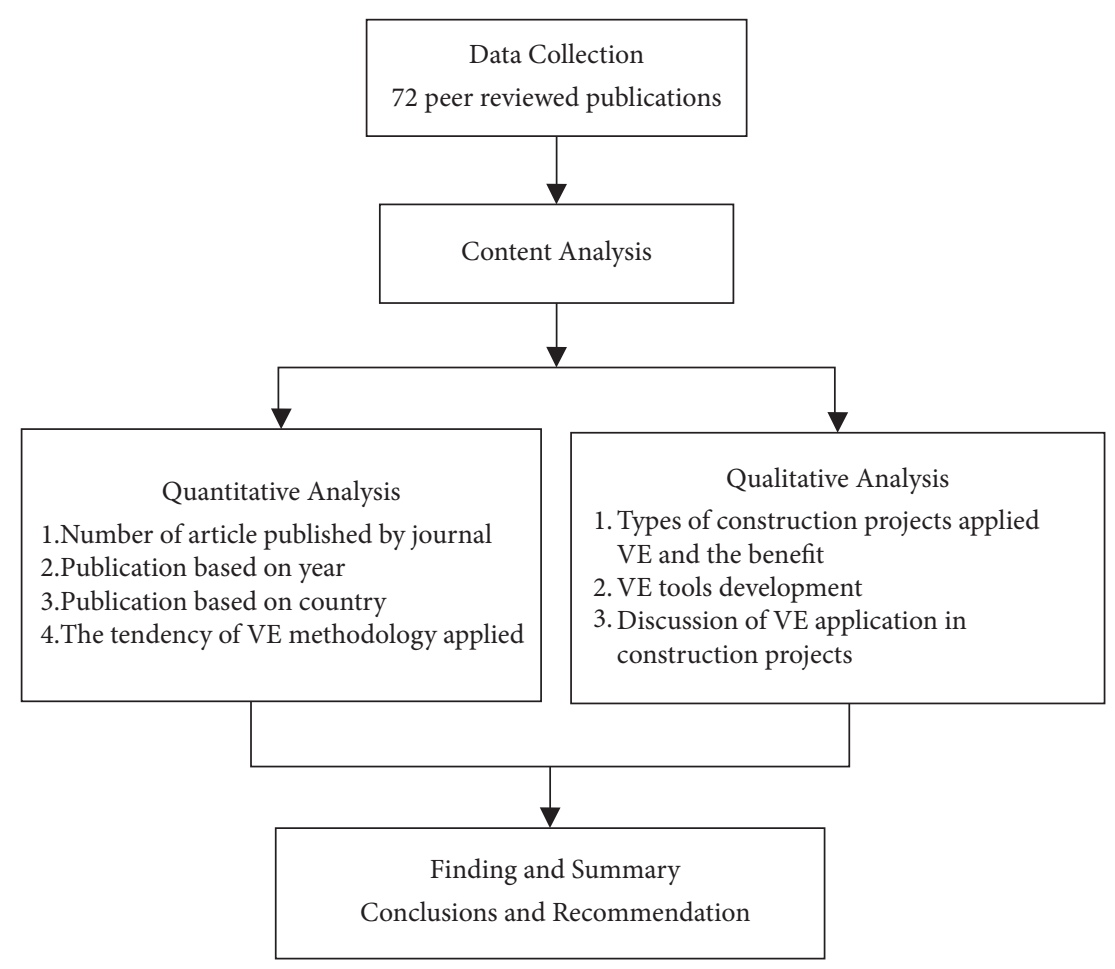

FIgURE 2: Content analysis process.

mainly because it provides both semiquantitative and qualitative comparisons, allowing for the identification of common limitations and research gaps that could lead to further advancement of VE practice.

Studies were selected by keyword search for combined use of related terms of "construction" and "value engineering" in the peer-reviewed construction industry and research journals, as well as conference proceedings searched through electronic databases including Science Direct, Google Scholar, and Scopus, followed by an abstract review to assess relevance. Each technical paper selected from the specified period was analysed, and data were extracted and recorded. Of particular interest was research on topics related to general VE practice, supporting tools, objectives, outcomes, and technology applications. To ensure the relevance of the findings, the search period was constrained to work published from 2009 to the present. Each paper was then reviewed to ensure it met certain criteria of the review.

\section{Results}

4.1. Descriptive Summary of Journals Reviewed. The following sections provide a summary overview of the key attributes including publishing journal, geographic location, and area of application of the studies found in the literature search.

4.1.1. VE in Construction Publications by Journal. The search results identified 72 peer-reviewed academic or industry publications concerned with the topics of advances in project management, civil and construction engineering, and construction management. Of the results, 57 were from academic or industry journals and 15 were published conference proceedings. The limited result of 72 publications is likely due to VE application in construction being a niche area of research. Table 1 shows that, with seven articles, the International Journal of Project Management leads in the publication of VE research-related construction projects, followed by International Journal of Construction Management with four articles: Automation in Construction, International Journal of Scientific \& Engineering Research, Journal of Construction Engineering and Management, and Procedia Social and Behavioural Sciences, each with three articles. The bulk of articles is found in journals focused on construction and project management as would be expected with $\mathrm{VE}$ viewed as an enabling tool for improving value.

Five journals published two articles related to VE in construction. The remaining 38 journals published a single paper meeting the search criteria for the period of interest. The search shows that although the distribution is across a wide number of journals, and the number of VE articles published per journal is largely limited. One of the main industry-based journals for VE is the "Value Management Journal" which during the period of interest only had a single publication that met the search criteria of $\mathrm{VE}$ in construction.

The distribution of journals found shows that research related to the application to $\mathrm{VE}$ is mostly published in journals concerned with research in the field of project management, construction, and engineering, whereas the $\mathrm{VE}$ industry journals were limited in their contribution to VE research for the construction industry. 
TABLE 1: Distribution of journal publications.

\begin{tabular}{|c|c|c|}
\hline No & Journal & No \\
\hline 1 & International Journal of Project Management & 7 \\
\hline 2 & International Journal of Construction Management & 4 \\
\hline 3 & Automation in Construction & 3 \\
\hline 4 & International Journal of Scientific and Engineering Research & 3 \\
\hline 5 & Journal of Construction Engineering and Management & 3 \\
\hline 6 & Procedia Social and Behavioural Sciences & 3 \\
\hline 7 & Built Environment Project and Asset Management & 2 \\
\hline 8 & International Journal of Civil Engineering and Technology & 2 \\
\hline 9 & International Journal of Production Economics & 2 \\
\hline 10 & IOP Conference series. Earth and Environmental Science & 2 \\
\hline 11 & World Journal of Engineering and Technology & 2 \\
\hline 12 & Advances in Civil Engineering & 1 \\
\hline 13 & Ain Shams Engineering Journal & 1 \\
\hline 14 & Alexandria Engineering Journal & 1 \\
\hline 15 & American Journal of Engineering and Applied Sciences & 1 \\
\hline 16 & ARPN Journal of Engineering and Applied Sciences & 1 \\
\hline 17 & Australian Journal of Basic and Applied Sciences & 1 \\
\hline 18 & British Journal of Applied Science and Technology & 1 \\
\hline 19 & Building and Environment & 1 \\
\hline 20 & Construction Management and Economics & 1 \\
\hline 21 & European Online Journal of Natural and Social Sciences & 1 \\
\hline 22 & Expert Systems with Applications & 1 \\
\hline 23 & Imperial Journal of Interdisciplinary Research & 1 \\
\hline 24 & Indian Journal of Science and Technology & 1 \\
\hline 25 & Indian Journal of Fundamental and Applied Life Sciences & 1 \\
\hline 26 & International Journal of Built Environment and Scientific Research & 1 \\
\hline 27 & International Journal of Current Advanced Research & 1 \\
\hline 28 & International Journal of Engineering Sciences and Research Technology & 1 \\
\hline 29 & International Journal of Innovative Research in Advanced Engineering & 1 \\
\hline 30 & International Journal of Innovative Research in Science, Engineering and Technology & 1 \\
\hline 31 & International Journal of Latest Trends in Engineering and Technology & 1 \\
\hline 32 & International Journal of Optimization in Civil Engineering & 1 \\
\hline 33 & International Journal of Real Estate Studies & 1 \\
\hline 34 & International Journal of Science and Research & 1 \\
\hline 35 & International Research Journal of Applied and Basic Sciences & 1 \\
\hline 36 & Journal of Chemical and Pharmaceutical Research & 1 \\
\hline 37 & Journal of Chinese Institute of Engineers & 1 \\
\hline 38 & Journal of Civil Engineering and Management & 1 \\
\hline 39 & Journal of Management in Engineering & 1 \\
\hline 40 & Journal of Physics: Conference Series & 1 \\
\hline 41 & Journal of Traffic and Transportation Engineering & 1 \\
\hline 42 & Procedia Engineering & 1 \\
\hline 43 & Procedia Environmental Sciences & 1 \\
\hline 44 & Procedia Technology & 1 \\
\hline 45 & Renewable Energy & 1 \\
\hline 46 & Research Journal of Applied Science & 1 \\
\hline 47 & Shanlax International Journal of Arts, Science and Humanities & 1 \\
\hline 48 & Sustainability & 1 \\
\hline 49 & Technological and Economic Development of Economy & 1 \\
\hline 50 & Value Management Journal & 1 \\
\hline Total & & 72 \\
\hline
\end{tabular}

4.1.2. Geographic Location. Figure 3 shows the distribution of VE research by country/region in which the study was situated. Over the period of interest, India led with 12 articles, and Iran with six articles followed by Malaysia with seven, while Egypt, Hong Kong, and Indonesia had five. This distribution suggests a strong interest in VE in developing countries across Asia and the Middle East as well as countries where VE is a well-established and often a mandated requirement for certain projects. However, mandating VE for projects does.

There is a lean towards a greater number of publications being generated from developing countries. Research from India and Ghana advocates for the greater use of VE in projects in developing countries due to the ability to improve efficiencies for project delivery $[17,18]$. With rapid economic and population growth and the resulting need for 


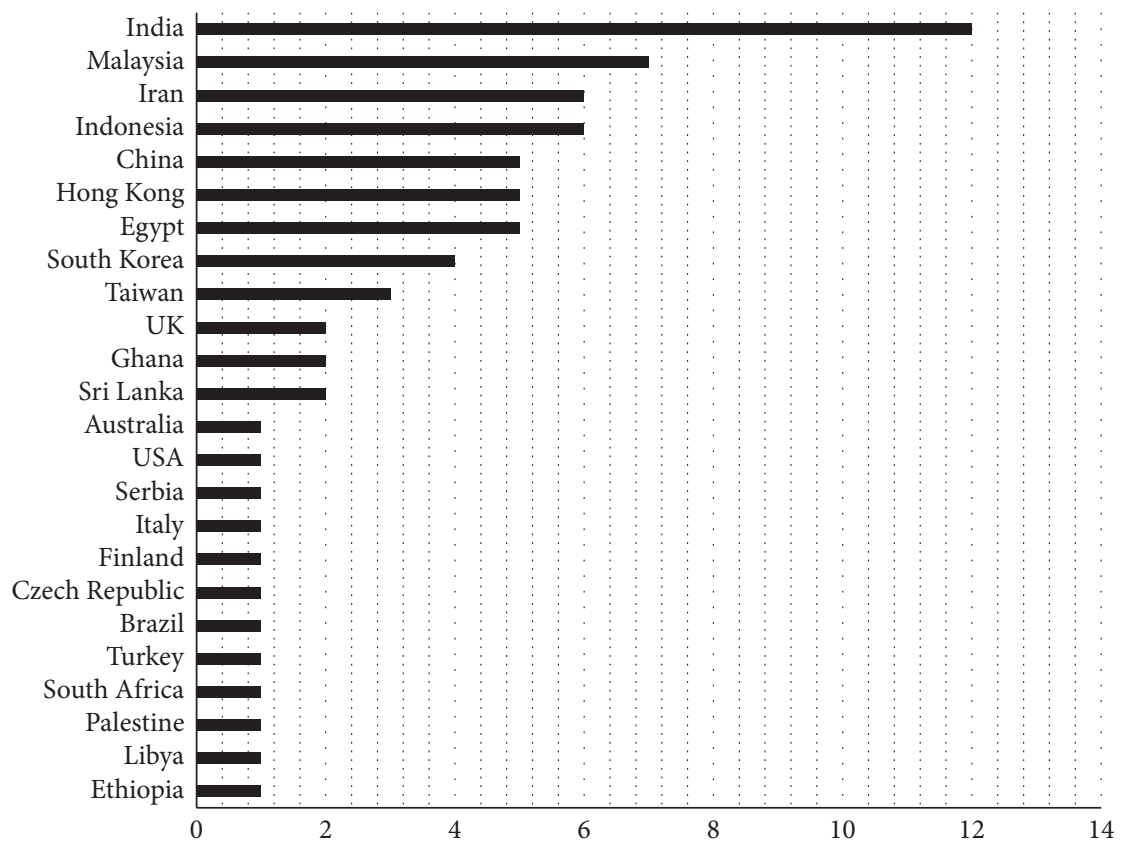

FIgURE 3: Number of publications by country/region of study.

rapid infrastructure development, VE has much to offer in such scenarios. Conversely, developed countries where VE practices are already well-established and often mandated are underrepresented in the studies found matching the search terms applied. There is potential that such research is missed through using different terminologies for the value improvement practices applied. The comparison of different value improvement practices and methodologies is not within the scope of this study; however, this should be considered in future research.

Figure 4 shows the absolute numbers of VE-related articles in construction publications during the period of interest as a year-by-year trend. Beginning with single article in both 2007 and 2008, research interest in the field rose quickly to seven publications in 2011, before falling back to four in 2012, and then, later increased after 2014 with a peak of 12 publications in 2016, followed by a sharp drop to only two publications in 2019. Despite this broad year-to-year fluctuation, the average is 4.8 publications per year. Overall, there has been an increasing trend in research of $\mathrm{VE}$ in construction from 2007 to 2021, given that the growing pressure for increased innovation and efficiency in construction operations and research of VE should be an area of continued research interest.

The research focus varies across the different elements of the VE methodology. Figures 4 and 5 show the key VE study phases covered by the studies reviewed, including studies focused on the general professional practice of VE. In terms of research content, approximately $55 \%$ of publications included the VE evaluation phase, which is one of the most critical steps of the VE process. Such research focuses on overcoming the limitations encountered when evaluating options, generating new ideas, and capturing learning from previous projects. Approximately $41 \%$ of articles cite the information, function analysis, and creativity phases, which are key value steps in VE and often the most challenging to gain the greatest value. Comparatively, the discussion of the development and presentation phases is relatively limited. Furthermore, the postworkshop stage was only discussed in $19 \%$ of the reviewed publications, where the focus is on assessing and reflecting on VE workshop performance after project completion to identify opportunities to improve VE workshop practices. The key theme is that while the VE process remains relevant in construction project that there is interest in the reliable understanding of the problem, generation of alternatives, and learning from previous workshops.

4.1.3. VE Application in Construction Projects. The underlying methods used for VE implementation for construction projects support an almost universal approach that can be successfully applied to a distinct range of projects and can also benefit a range of construction systems [19]. VE is used to effectively drive improvements in construction project value, helping to enhance public perceptions of the industry [20]. VE has been shown to effectively reduce project life cycle costs while maintaining or improving overall project value, thus indirectly contributing to national development [6].

The past decade has seen VE applied to a diverse range of construction projects, focusing on not only value assessment in relation to project lifecycle costs, but also other aspects of project value [13]. Table 2 summarizes the range of VE applications in construction projects over the past decade. The studies reviewed generally focused on four key construction domains: structure, geotechnical, transportation, and construction management. Thirteen of 18 reviewed articles focused on conventional goals of reduction of overall lifecycle cost, thus increasing value by identifying suitable 


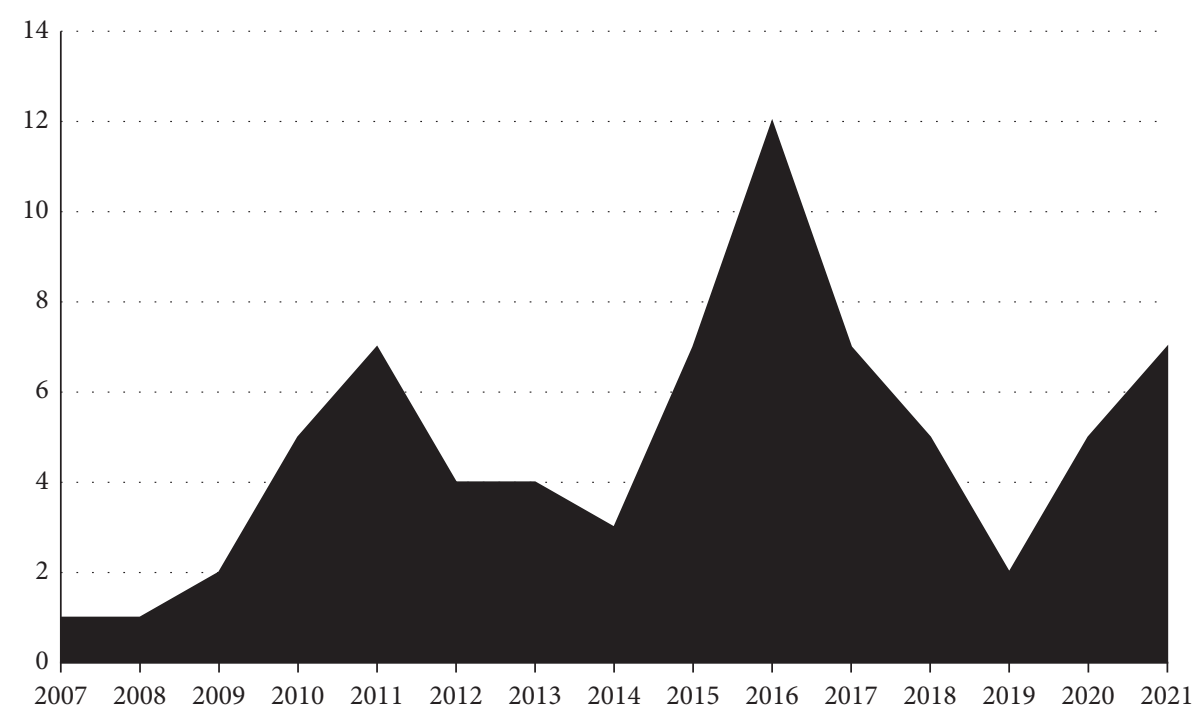

FIgURE 4: The count of publications by year.

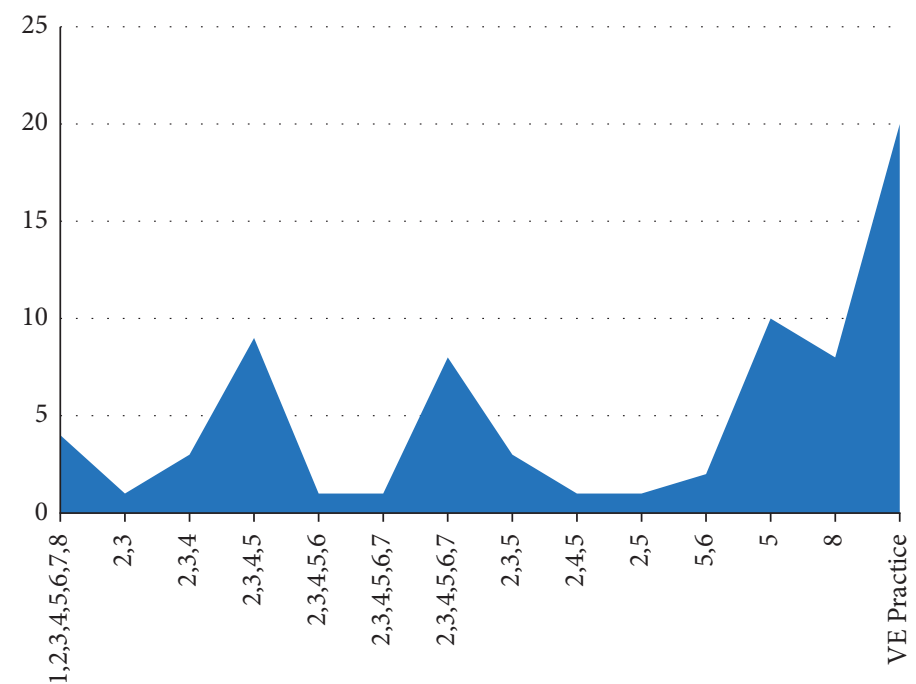

VE Workshop phases - 1:pre-workshop, 2:information. 3:function, 4:creativity, 5:evaluation. 6:development, 7:presentation, 8:post-workshop, and VE Practice:general professional practice of VE

Figure 5: Publications based on VE workshop phases. VE workshop phases-1: preworkshop, 2: information, 3: function, 4: creativity, 5: evaluation, 6: development, 7: presentation, 8: postworkshop, and VE practice: general professional practice of VE.

alternatives to high-cost construction project elements while maintaining or improving function outcomes. The literature also shows that, as construction projects become more complex along with growing expectations for overall environmental and social sustainability, there is potential to expand the concept to additional project functions. For example, the study by Rachwan et al. [21] that focused on delivering improved project sustainability through increased energy efficiency and Robati et al. that integrated carbon and project cost into the VE assessment.

4.2. VE Tools. Another notable area of VE research focus has been the application of technology to develop tools to promote the effectiveness and efficiency of the VE methodology.
Some aspects of the VE process are repetitive and timeconsuming, including idea generation, alternative evaluation, and VE workshopping with team members across multiple locations. Effective VE implementation requires the input of diverse stakeholders and related experts, and efficient use of resources, such as time, present an ongoing challenge. Over the past decade, 12 articles have addressed the use of VE tools to facilitate VEW. Specifically, several researchers have adapted parts of the VE methodology such as FAST, value index, and Pareto Law. Table 3 summarizes the methodology and tools used in the present research.

The primary area of interest regarding VE technology has focused on the development of platforms to capture and reuse the information generated during the various VEW phases. Throughout the workshop, substantial amounts of 
TABLE 2: VE application in construction projects.

\begin{tabular}{|c|c|}
\hline Item & Benefits realized from the application of VE \\
\hline \multicolumn{2}{|l|}{ Structure } \\
\hline Desalination plant & $\begin{array}{l}\text { Successfully reduced construction costs by } 10.33 \% \text { and reduced annual operating costs by about } \\
\text { US } \$ 330,000\end{array}$ \\
\hline Masonry lining & Cost savings of $\mathrm{Rp} 15,180,000.00$ or $47.6 \%$ for 50 -meter tertiary irrigation channel \\
\hline Offices complex & Reduced concrete costs by $3.90 \%$; reduced rebar diameter by approximately $50 \%$ \\
\hline Gas refinery & Reduced overall construction costs by $41 \%$ \\
\hline Review of slip form (S.F.) & $\begin{array}{l}\text { VE is used to adopt S.F. construction methods for special structures such as high-rise buildings, } \\
\text { chimneys, silos, piers, towers, and heavy concrete offshore platforms }\end{array}$ \\
\hline Large-scale residential & Reduced project energy consumption by $7 \%$, and reduced project costs by $40 \%$ \\
\hline Educational building & $\begin{array}{l}\text { VE achieves energy consumption reduction and optimization in the context of macroeconomic } \\
\text { policies }\end{array}$ \\
\hline $\begin{array}{l}\text { District cooling and heating } \\
\text { (DCH) system }\end{array}$ & $\begin{array}{l}\text { VE is used to evaluate different DCH schemes, analyse system function and cost in the comprehensive } \\
\text { evaluation, and provide information for the final decision }\end{array}$ \\
\hline Housing & Reduced system development costs by as $68,816 \$$ \\
\hline Residential building & Reduced project costs by $11,94,000$ Rs \\
\hline Drain coverings & $\begin{array}{l}\text { VE is used to explain the environmental impact of drain coverings and to compare alternatives while } \\
\text { accounting for life cycle cost }\end{array}$ \\
\hline \multicolumn{2}{|l|}{ Transportation infrastructure } \\
\hline High speed rail (HSR) & Construction savings of US $\$ 2,663,970$ and maintenance savings of US\$17,197,120 \\
\hline Ship & $\begin{array}{l}\text { VE study (VES) defined the value index using information gained during the information and } \\
\text { functional phases to generate alternatives selected in the creative phase }\end{array}$ \\
\hline Highway & $\begin{array}{c}\text { Approximate savings of } \$ 43,000,000 \text { (6\% of total project costs), and reduced construction schedule by } \\
12 \text { months }(17 \%)\end{array}$ \\
\hline Mass rapid transit (MRT) & Cost savings of $30 \%$ and $14 \%$ for two different MRT routes \\
\hline Airport rail link & $\begin{array}{l}\text { VES is used to generate new functions and concept designs, including a three-level multifunction } \\
\text { underground passage for MRT, Airport Rail Link, and storm drainage. This design reduces traveller } \\
\text { congestion, decreases flooding in the greater Jakarta area, and increases airport accessibility. Life cycle } \\
\text { cost analysis results confirmed technical and financial viability }\end{array}$ \\
\hline
\end{tabular}

Construction management

Interchange

VE is used to ensure the safety of an existing pipeline corridor beneath the project area. The first VEW step was to identify the unnecessary function through the functional analysis

Geotechnical

Expressway

Evaluation of expressway expansion on soft ground improved functionality by $80.8 \%$ with cost savings of $26.8 \%$ for alternative $1,11.6 \%$ for alternative 2 , and $47.3 \%$ for alternative 3

information are created across multiple formats, raising information management challenges, especially in large complex projects. Another focus of concern is knowledge management, as the VE process relies heavily on the creativity and collective expertise of the stakeholders. As such, the generation of ideas and sharing of experience from previous projects have long been an area of interest for VE professionals. Lee et al. [22] developed the REmembering Tool for Reusing the Ideas Evolved in Value Engineering (RETRIVE) tool to capture proposals from previous VEWs and assist in suggesting solutions during VEW.

The evaluation of ideas is often challenging with a multitude of ideas and opinions. As a solution, Dahooie et al. [23] proposed a multicriteria decision-making approach to identifying and prioritizing cost reduction solutions while maintaining value. An evaluation framework provides a consistent and objective method of evaluating proposed solutions.

4.3. VE Practices. The reviewed literature shows that most VEWs are conducted using the classic six job plan phases. However, within the sample dates of 2007-2021, researchers increasingly began to focus on assessing VEW performance in 2010 (Figure 6) to maximize VE process outcomes, suggesting increased research interest in improving processes to optimize outcomes. Perhaps one of the most interesting aspects of the research on VE practice is the growing use of technology to support different aspects of the workshop process. In particular, the past decade has seen the development of several specific VE technologies, which are computer-based programs designed to enhance the VE process. Six of them are the most popular, namely, VE-Knowledge Management System (VE-KMS) [4], RETRIEVE [22], BIM-based Idea Bank [24], ELECTRE III [25], GDSS-IVMS [26], and LiVE [27].

VE-KMS and RETRIEVE were both published in 2009 and are designed to assist VE practitioners during the creativity phase in retrieving ideas from past VE cases for consideration and application in current workshops. This approach can help introduce and capture ideas that otherwise may not be generated through conventional approaches, while also creating a repository of knowledge and ideas through building on already commonly used tools such as TRIZ. While such tools can be of assistance to the VE process, VE practitioners need to ensure that such tools do not come at the expense of new creative thinking among 
TABle 3: VE tools.

\begin{tabular}{|c|c|c|}
\hline No & Tools & Methodology \\
\hline 1 & Original VE approach & $\begin{array}{l}\text { Using the original VE job plan including information, function analysis, } \\
\text { creativity, evaluation, development, and presentation }\end{array}$ \\
\hline 2 & FAST (functional analysis system technique) & $\begin{array}{c}\text { FAST diagram is a technique developed to improve function determination, } \\
\text { classification, and evaluation according to the How-Why logic formula, with } \\
\text { results plotted into a block diagram }\end{array}$ \\
\hline 3 & Value index & $\begin{array}{l}\text { Value is defined as the ratio of performance to cost Value }(\mathrm{V})=\text { Performance } \\
\qquad(\mathrm{P}) / \text { Cost }(\mathrm{C})\end{array}$ \\
\hline 4 & $\begin{array}{l}\text { VE-KMS (value engineering knowledge } \\
\text { management system) }\end{array}$ & $\begin{array}{l}\text { Integrates TRIZ into the creativity phase, including analysis of: (1) technical } \\
\text { contradictions, (2) physical contradictions, (3) substance field, and (4) } \\
\text { technological evolution. This allows workshop participants to maximize the } \\
\text { impact of their engineering experience and proficiencies, as explicit knowledge. } \\
\text { The system saves this knowledge in a database for continued use in the VE } \\
\text { process and is continuously updated }\end{array}$ \\
\hline 5 & $\begin{array}{l}\text { RETRIEVE (remembering tool for reusing the ideas } \\
\text { evolved in value engineering) }\end{array}$ & $\begin{array}{l}\text { VE proposals are collected from previous VEW sessions for use in reference to } \\
\text { current problems. RETRIEVE identifies similarities between new and old cases } \\
\text { using an algorithm developed in VBA for MS Office }{ }^{\mathrm{TM}} \text { and MS Office Access }{ }^{\mathrm{TM}}\end{array}$ \\
\hline 6 & Fuzzy case-based reasoning & $\begin{array}{c}\text { Integrates case-based reasoning (CBR) with fuzzy logic concepts to measure } \\
\text { similarities of new and previously solved problems }\end{array}$ \\
\hline 7 & ELECTRE III & $\begin{array}{l}\text { ELECTRE III is used to rank alternative solutions in the evaluation phase to aid } \\
\text { decision-making }\end{array}$ \\
\hline 8 & GDSS-IVMS (group decision support system) & $\begin{array}{c}\text { Creates a virtual online VE workshop phase, mooting the need for face-to-face } \\
\text { meetings }\end{array}$ \\
\hline 9 & BIM-based idea bank & $\begin{array}{l}\text { Using 2D BIM objects, workshop participants may reuse previous VE cases and } \\
\text { ideas to produce alternative solutions for current projects }\end{array}$ \\
\hline 10 & LiVE (Lean integrated VE) & $\begin{array}{l}\text { Integrates lean concepts to eliminate waste in VE processes to identify necessary } \\
\text { functions through creating an } 8 \text {-phase job plan }\end{array}$ \\
\hline 11 & Performance assessment & $\begin{array}{c}\text { Used in the postworkshop phase to evaluate the success of results generated from } \\
\text { the workshop phase. It also appraises workshop process performance as a } \\
\text { reference to improve future workshops }\end{array}$ \\
\hline 12 & Pareto's law & Holds that $80 \%$ of the cost or risk can be found in $20 \%$ of the project's function \\
\hline 13 & BIM integration & Integrating building information modelling with value engineering \\
\hline 14 & Grey multicriteria decision-making & $\begin{array}{l}\text { Framework for utilizing a value engineering approach to supply chain cost } \\
\text { management and overcoming the limitations with VE by utilizing grey } \\
\text { multicriteria decision-making }\end{array}$ \\
\hline
\end{tabular}

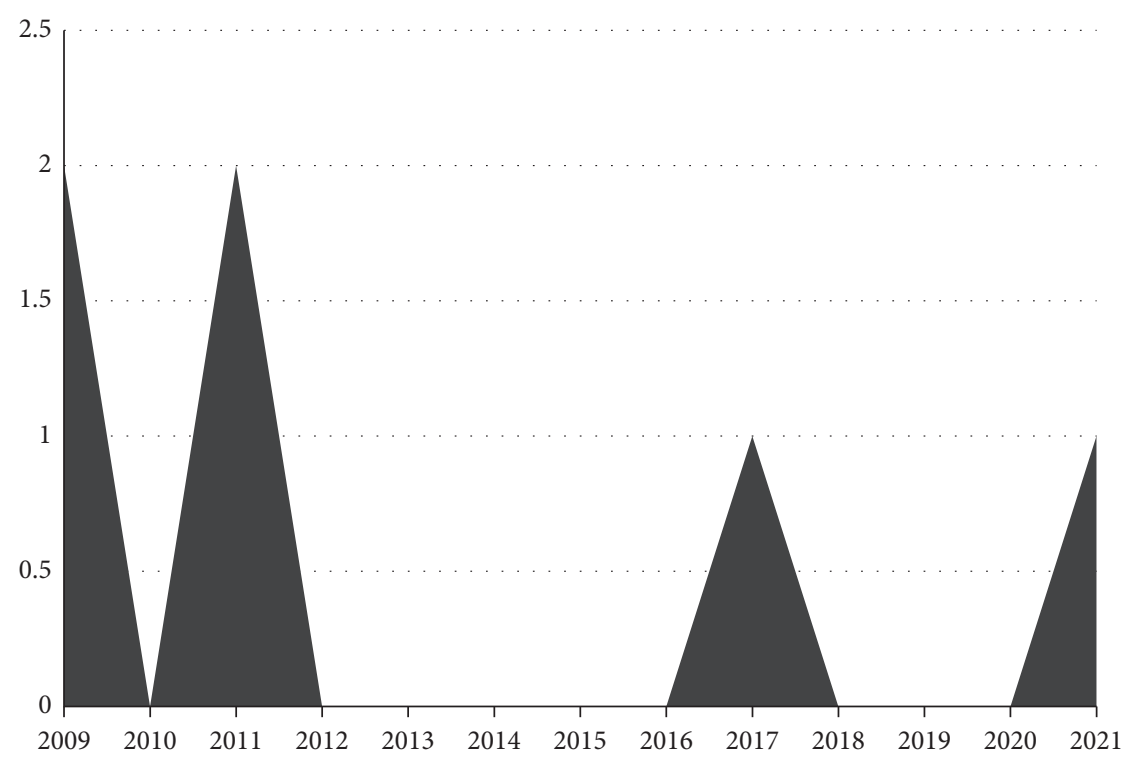

FIGURE 6: Number of VE articles related to technology development by year. 
current VEW participants. Among the tools reviewed, GDSS-IVMS is the only software platform designed to support all phases of a VEW, including the stages of preworkshop, workshop, and postworkshop. This end-to-end VEW tool connects VEW participants virtually without the need for face-to-face meetings. It also draws clear functional analysis system technique (FAST) diagrams and records completed VE cases as a resource repository of new ideas. The other technologies reviewed provide limited support up to the evaluation phase.

It stands to reason that the continuous advancement of software and analysis methods would extend to technologies and tools for VE. Nevertheless, the work to date has been generally limited to selected VEW steps rather than process wholistically. No particular VEW step is more important than another, and a robust end-to-end tool would be of benefit for VE practitioners, especially with factors such as a growing decentralized workforce operating across multiple locations and increasing complexity of construction projects. Reports on VE technology were largely concentrated in 2009 and 2011 (two reports each year), suggesting a relatively modest interest in the advancement of tools to support VEWs. However, with the increased use of globally distributed teams, the normalization of remote working is expected to drive the future development of improved VE tools. Technologies to facilitate remote working have come to the forefront during the COVID-19 pandemic with many teams working remotely. The COVID-19 situation resulted in a rapid change in digitalized processes; however, further time and research are needed to understand how these processes are integrated within the whole life cycle of a construction project [28].

\section{Discussion}

VE has been widely used in the construction industry to improve project outcomes. VE practices have been improved over recent years by enhancing the methodology and developing new means to overcome existing process limitations [29].

The present review shows that VE can be applied to select and evaluate nearly any kind of construction system or project [19]. This flexibility means that VE remains relevant and can be expanded for different project objectives such as reviewing potential layouts, optimizing construction value strategies, and site and access point selection [29]. VE brings many advantages to construction projects, particularly in optimizing the use of resources while achieving the desired functions and can be integrated with other project functions. Research has seen VE being integrated with other project administration functions. Masengesho et al. [30] investigated the integration of risk management with VE with the aim to focus on improving project delivery efficiency and risk reduction at the same time. Furthermore, combining RM and VE in a single workshop could avoid duplication and deliver better project outcomes and value. VE is also scalable, making it well suited for projects of widely varying size and complexity. However, relatively little research has examined scalability issues, particularly in terms of resource investment depending on project size or value.

The reviewed literature shows varied motivations for implementing $\mathrm{VE}$, including to enhance various project values based on the customer's area of interest [31], minimize unnecessary costs $[4,20,24,32,33]$, maximize product quality $[2,29,34]$, meet function requirements [24, 29], and improve delivery time efficiency [35]). The final goal of using $\mathrm{VE}$ in construction projects is to improve the outcome [36].

5.1. Defining value in Construction Projects. Quality and value are strongly related components of VE as they can be readily assessed through function analysis. In contrast with cost control, VE focuses on the design function, integrates specific client requirements, and strives to enhance quality and functional performance [31]. Function analysis is an established tool for defining problems, generating ideas, examining project potential, and maximizing value. The FAST diagram is a defining attribute of VE, which separates it from other techniques. Value of the resources expended is the primary objective of $\mathrm{VE}$ and is achieved by presenting all required functions at the lowest life cycle cost, while simultaneously ensuring the quality and performance of the final project delivery [36].

Maximizing value in construction projects can be broadly grouped into three dimensions [31]: contract compliance, construction delivery, and project sustainability. Following the completion of the project, there is the ongoing maintenance [37]. The definition of "value" for a construction project is achieving the required function performance at the cheapest life cycle costs. In terms of the end of asset lifecycle, value may not be strictly defined in financial terms, but can be reflected in terms of a broader range of factors such as environmental health, safety, and security [13]. The different definitions of value do not need to be evaluated in isolation. Robati et al. [38] proposed a carbon value engineering (CO2VE) framework for assessing capital cost and embodied carbon simultaneously. To promote the adaptation of $\mathrm{VE}$ as a cost-saving incentive program in construction projects, the "value" clauses should be explicitly included in the contract documents and incentivize contractors are to optimize the techniques applied during construction project time [31, 39]. Such incentives should consider all different definitions of value relevant to the project and stakeholders.

With growing expectations for improved sustainability and safety in construction, the definition applied to this value appears to be expanding beyond a simple function over cost. Trends in applied VE research appear to show that costs can include social costs through the use of factors such as safety and environmental attributes needing protection or enhancement. While some of the reviewed VE studies touch on elements of energy efficiency and safety, the applicability to such novel applications requires further investigation. Consideration needs to be given to not only how to best incorporate different value concepts into VE studies but also how VE can be used as a tool to integrate a wider range of value concepts into a project. 
5.2. VE Throughout Construction Stage. VE plays a role at almost any stage of a construction project and can be conducted before, during, and after project completion $[34,40]$. Atabay and Galipogullari [35] agreed that VE can provide beneficial results at any time of the product, system, or procedure life cycle. VE can potentially be applied during the construction stage with the part contractor being awarded a share of any cost savings [19, 31]. Most experts suggest the most productive time to employ VE is in the early stage of the construction project with an aim to influence the fundamental direction of the project $[20,29]$, as this stage provides the greatest flexibility for making changes without imposing additional delays and costs. After construction has begun, such opportunities are harder to come by and often entail considerable expense [36].

The most appropriate phase to undertake a VEW is the precontract phase [36]. Surlan et al. [5] argued that the highest potential for successful VE implementation is in the preconstruction stage prior to design decisions. Conducting a VEW in an early stage could overcome the lack of practitioner skills or VEW market to still provide the best plan [13]. Perhaps one of the least considered stages of the asset life cycle is the end of serviceable life. Most of the construction-related project management literature is focused on project life cycles up to the commissioning stage and handed over to the client, with little attention given to the end-of-life cycle. At the end of an asset's life cycle, careful consideration must be given to the decommissioning process including disposal or repurposing of the waste materials. Invernizzi et al. [13] emphasized that VE can also bring clarity to project decommissioning and waste management operations.

5.3. International VE Research. VE is an established primary method to maximize the efficiency of construction projects in developed countries, ensure the delivery of quality for users, and contribute to infrastructure development objectives [29]. Conversely, VE is not as established in the construction industries of developing countries [39]. Several developing countries have implemented requirements for the obligatory inclusion of VES into their construction projects. In Malaysia, the Economic Planning Unit requires VE implementation for all types of public projects costing beyond RM 50 million [29, 41], while Hong Kong requires VEW for projects exceeding $\mathrm{HK} \$ 200$ million [42] and Indonesia requires $\mathrm{VEW}$ for projects with a total building area exceeding $12,000 \mathrm{~m}^{2}$ or eight floors (Ministry of Public Works Regulation No. 45/2007). However, VE has yet to be fully implemented in the construction industries of South Africa or Nigeria [29], Ghana [18, 31], or Sri Lanka [36].

Governmental regulations are a key factor in driving the adoption of VE for construction projects. According to Surlan et al. [5], VEW is complex and requires a skilful facilitator or a CVS (certified value specialist). Barriers to the adoption of VE can be minimized by hiring construction professionals and by the national and regional governments mandating or incentivizing the application of VE [29]. However, careful consideration should be given to the mandated framework. Experience in Indonesia shows that while having a legal requirement for VE on certain public projects, the execution still needs to be carefully managed and regulated to realize the full benefits of VE [43].

5.4. VE Applications in Construction Design. VE concepts are used in projects because design and construction materials are a significant component of a construction project's cost [32]. VE can be applied in the design review to ensure essential function delivery with the lowest cost. Shahhosseini et al. [44] suggested that owner eagerness to accelerate project development limits innovation in the design stage. Construction project quality could be optimized by auditing all of the project stakeholder decisions in terms of maximising design value [29], and design problems can be effectively identified and remedied by applying $\mathrm{VE}$ at the design stage.

Generating creativity and finding suitable alternatives can be a time-consuming step in a VEW. Integrating VE with software tools such as TRIZ, VE-KMS, RETRIEVE, and BIM systems provides a multitude of design alternatives widely used in the construction industry. TRIZ is a systematic problem-solving tool, which contains several different concepts, tools, and principles to frame and analyse problems to produce creative project solutions. VE-KMS expands on TRIZ by incorporating TRIZ tools to make the creativity phase more systematic and more organized that enables the VE team to control the creative process and learn from previous VEWs. Like TRIZ, RETRIEVE has a case library and retrieval algorithm. Building information management (BIM) systems have seen increasing use for supporting VE $[45,46]$. The BIM-based idea bank creates a $2 \mathrm{D}$ construction illustration of the retrieved case to give VE participants a clear understanding of the construction outcomes [24].

5.5. Supporting the Success of the VEW. Interactive VEW sessions help provide information necessary to overcome stakeholder hesitation [13]. The stakeholders' concerns need to be taken as the primary consideration as they determine the project goals [29]. Chen et al. [20] posited that VEW success relies on certain factors: (1) job plan execution, (2) the personality of VE facilitator, (3) input from the project owners, (4) the workshop plan and its relationships within the design team, and (5) the project character. The research illustrates that the success with the VE method heavily relies on the leadership and experience of the facilitator. Therefore, as a weakness of the VE methodology, careful consideration must be given to the skills and personal attributes of the VEW leadership, in particular the discipline and commitment to the full VE methodology under pressure of limited time and resources.

Success requires the involvement of all principal stakeholders and, where possible, regulatory representatives should be included to provide additional expertise and alternative solutions [8, 12, 47-49]. Moreover, the common constraints experienced during VEW can potentially be overcome through the judicious application of VE technology such as GDSS-IVMS, which supports participants in the 
decision-making process through information sharing, drawing FAST diagrams, and generating and evaluating ideas.

\section{Conclusions}

VE has been used in practice for over 70 years. Over this time, the VE methodology has been shown to be an effective tool for improving value and reducing overall life cycle costs in a wide range of construction projects. Its fundamentals remain largely unchanged, but this review of VE research in the construction industry over the past decade shows a continuously evolving approach to the application and practice of VE to meet contemporary needs. The outcomes of this research are beneficial for both research and operations in the construction industry and ensure that it remains a valuable tool for the construction industry.

While VE remains a useful tool for delivering value through reducing life cycle cost without compromising the function, there is an increasing expectation that construction project costs refer to more than just financial costs. To meet these growing expectations, there is an opportunity for VE to consider various social and environmental costs as part of a more holistic and integrated approach to value. Expanding the role of VE to include life cycle aspects beyond financial costs provides greater scope for the application of VE in construction projects.

VE appears to be well established in developed countries, whereas developing countries are continuing to expand VE involvement in construction projects. In many respects, developing countries have the most to gain from VE implementation through improved project performance and cost optimization. However, research on the best practices and benefits achieved from mandating VE is limited and warrants further investigation to assist developing countries in encouraging the adoption of VE.

Ongoing VE research promotes continuous improvement, especially in terms of expanding VE considerations beyond cost. During the past decade, researchers have continuously expanded the understanding of VE to upgrade the efficiency and productiveness of VE practice. Current work focuses on integrating VE with other disciplines, VE applications in diverse project domains, assessing VE performance, and the development of new VE technologies. The impact of VEW participation on project outcomes is an area of research worthy of further investigation. This broad review highlights some of the key areas of interest, which require future investigation using systematic approaches to support the continued delivery of value in the ever-changing and evolving construction industry.

\section{Data Availability}

The data used to support this study are from previously reported studies and datasets, which have been cited at relevant places within the text as references.

\section{Conflicts of Interest}

The authors declare that there are no conflicts of interest regarding the publication of this paper.

\section{Acknowledgments}

This work was financially supported by the Ministry of Science and Technology (MOST 110-2221-E-224-012) in Taiwan.

\section{References}

[1] N. Tom and V. Gowrisankar, "Value engineering in residential house construction," International Journal of Civil Engineering \& Technology, vol. 6, no. 6, pp. 46-52, 2015.

[2] A. Ismail, R. Aminzadeh, A. Aram, and I. Arshad, "Value engineering application in highway projects," American Journal of Engineering and Applied Sciences, vol. 3, no. 4, pp. 699-703, 2010.

[3] G. Lin, G. Q. Shen, M. Sun, and J. Kelly, "Identification of key performance indicators for measuring the performance of value management studies in construction," Journal of Construction Engineering and Management, vol. 137, no. 9, pp. 698-706, 2011.

[4] X. Zhang, X. Mao, and S. M. Abourizk, "Developing a knowledge management system for improved value engineering practices in the construction industry," Automation in Construction, vol. 18, no. 6, pp. 777-789, 2009.

[5] N. Surlan, Z. Cekic, and Z. Torbica, "Use of value management workshops and critical success factors in introducing local experience on the international construction projects," Journal of Civil Engineering and Management, vol. 22, no. 8, pp. 1021-1031, 2016.

[6] M. M. Elsonoki, R. Yunus, S. R. Yunus, and A. R. Hamid, “The adoption of value engineering practices in the Libyan construction industry," in Proceedings of the IOP Conference Series: Earth and Environmental Science, vol. 498, IOP Publishing, Johor, Malaysia, 2020.

[7] I. A. Albalushi, F. Usman, and A. S. Alnuaimi, "Appraisal of value engineering in construction industry in Oman," Value World, vol. 36, no. 2, pp. 37-47, 2013.

[8] T. M. Adnan, S. Hasan, M. S. Rahman, and A. Das, "An analytical way to reduce cost of a product through value engineering employment (case study: walton)," International Journal of Scientific Engineering and Research, vol. 9, no. 2, pp. 527-533, 2018.

[9] W. T. Chen and S. L. Liao, "A job-plan based performance evaluation for construction value engineering study," Journal of the Chinese Institute of Engineers, vol. 33, no. 2, pp. 317-333, 2010.

[10] B. L. Tanko, F. Abdullah, Z. M. Ramly, and W. I. Enegbuma, "An implementation framework of value management in the Nigerian construction industry," Built Environment Project and Asset Management, vol. 8, no. 1, 2018.

[11] Z. Yuan, G. Q. Shen, K. H. Chung, Z. M. Ramly, T. W. Yu, and $\mathrm{H}$. Wang, "Experimental study on virtual value management workshop in Hong Kong," Journal of Management in Engineering, vol. 32, no. 2, 2016.

[12] M. R. Simanjuntak and Wijono, "The analysis of important variables of the value engineering model on residential high rise buildings in DKI jakarta, Indonesia," Imperial Journal of Interdisciplinary Research, vol. 3, no. 5, pp. 1037-1042, 2017.

[13] D. C. Invernizzi, G. Locatelli, M. Grönqvist, and N. J. Brookes, "Applying value management when it seems that there is no value to be managed: the case of nuclear decommissioning," International Journal of Project Management, vol. 37, no. 5, pp. 668-683, 2019. 
[14] K. A. Ahmed and R. K. Pandey, "Concept of value engineering in construction industry," International Journal of Science and Research, vol. 5, no. 4, pp. 1231-1237, 2013.

[15] I. M. Mahdi, K. M. Heiza, and N. E. Elenen, "State of the art review on application of value engineering on construction projects: high rise building," in Proceedings of the The International Conference on Civil and Architecture Engineering, vol. 4, no. 5, pp. 2742-2753, 2015.

[16] S. Moon, E. Choi, and S. Hong, "Creation of robust design alternatives for temporary construction in value engineering," Journal of Construction Engineering and Management, vol. 142, no. 3, 2016.

[17] A. K. Mansour and M. Abueusef, "Value engineering in developing countries," in Proceedings of the International Conference Data Mining, Civil and Mechanical Engineering (ICDMCME'2015), Bali Indonesia, 2015 Feb. 1-2.

[18] E. Kissi, E. B. Boateng, T. Adjei-Kumi, and E. Badu, "Principal component analysis of challenges facing the implementation of value engineering in public projects in developing countries," International Journal of Construction Management, vol. 17, no. 2, pp. 142-150, 2016.

[19] N. L. Rane and P. M. Attarde, "Application of value engineering in commercial building projects," International Journal of Latest Trends in Engineering and Technology, vol. 6, no. 3, pp. 286-291, 2016.

[20] W. T. Chen, P.-Y. Chang, and Y.-H. Huang, "Assessing the overall performance of value engineering workshops for construction projects," International Journal of Project Management, vol. 28, no. 5, pp. 514-527, 2010.

[21] R. Rachwan, I. Abotaleb, and M. Elgazouli, "The influence of value engineering and sustainability considerations on the project value," Procedia Environmental Sciences, vol. 34, pp. 431-438, 2016.

[22] S. Lee, C. Hyun, and T. Hong, "RETRIEVE: REmembering tool for reusing the ideas evolved in value engineering," Automation in Construction, vol. 18, no. 8, pp. 1123-1134, 2009.

[23] J. Heidary Dahooie, S. J. Hosseini Dehshiri, A. Banaitis, and A. Binkytè-Vèlienè, "Identifying and prioritizing cost reduction solutions in the supply chain by integrating value engineering and gray multi-criteria decision-making," Technological and Economic Development of Economy, vol. 26, no. 6, pp. 1311-1338, 2020.

[24] C.-S. Park, H.-J. Kim, H.-T. Park, J.-H. Goh, and A. Pedro, "BIM-based idea bank for managing value engineering ideas," International Journal of Project Management, vol. 35, no. 4, pp. 699-713, 2017.

[25] M. M. Marzouk, "ELECTRE III model for value engineering applications," Automation in Construction, vol. 20, no. 5, pp. 596-600, 2011.

[26] X. Luo, G. Q. Shen, S. Fan, and X. Xue, “A group decision support system for implementing value management methodology in construction briefing," International Journal of Project Management, vol. 29, no. 8, pp. 1003-1017, 2011.

[27] E. M. A. C. Ekanayake and Y. G. Sandanayake, "LiVE approach: lean integrated value engineering for construction industry," Built Environment Project and Asset Management, vol. 7, no. 5, pp. 518-533, 2017.

[28] K. Bennett and M. Mayouf, "Value management integration for whole life cycle: post COVID-19 strategy for the UK construction industry," Sustainability, vol. 13, no. 16, p. 9274 , 2021.

[29] I. Othman, A. F. Kineber, A. E. Oke, N. Khalil, and M. K. Buniya, "Drivers of value management implementation in building projects in developing countries," in Proceedings of the JICETS 2019 - Journal of Physics: Conference Series, vol. 1529, 2020 25-27 November 2019.

[30] E. Masengesho, J. Wei, N. Umubyeyi, and R. Niyirora, "A review on the role of risk management (RM) and value engineering (VE) tools for project successful delivery," World Journal of Engineering and Technology, vol. 09, no. 01, pp. 109-127, 2021.

[31] J. C. Danku and P. A. Antwi, "Perceived benefits of using value engineering on road projects in Ghana," World Journal of Engineering and Technology, vol. 08, no. 02, pp. 217-236, 2020.

[32] R. Janani, P. R. Chakravarthy, and D. R. Raj, "A study on value engineering and green building in residential construction," International Journal of Civil Engineering \& Technology, vol. 9, no. 1, pp. 900-907, 2018.

[33] N. Sawalhi and S. E. Namara, "Influence of applying value engineering concept in project case study: deir Al balah desalination plant," British Journal of Applied Science \& Technology, vol. 4, no. 1, pp. 89-112, 2013.

[34] M. Ravish and K. Vinoth, "A study on application of value engineering in residential building projects," Shanlax International Journal of Arts, Science and Humanities, vol. 4, no. 1, pp. 10-20, 2016.

[35] S. Atabay and N. Galipogullari, "Application of value engineering in construction projects," Journal of Traffic and Transportation Engineering, vol. 1, no. 1, pp. 39-48, 2013.

[36] W. H. S. Madushika, B. A. K. S. Perera, B. J. Ekanayake, and G. Q. P. Shen, "Key performance indicators of value management in the Sri Lankan construction industry," International Journal of Construction Management, vol. 20, no. 2, pp. 157-168, 2020.

[37] M. Niraj, "Selection of maintenance practice through value engineering," International Journal of Scientific Engineering and Research, vol. 2, no. 12, 2011.

[38] M. Robati, P. Oldfield, A. A. Nezhad, D. G. Carmichael, and A. Kuru, "Carbon value engineering: a framework for integrating embodied carbon and cost reduction strategies in building design," Building and Environment, vol. 192, p. 107620, 2021.

[39] P. Bowen, P. Edwards, K. Cattell, and I. Jay, "The awareness and practice of value management by South African consulting engineers: preliminary research survey findings," International Journal of Project Management, vol. 28, no. 3, pp. $285-295,2010$.

[40] A. Chougule, A. K. Gupta, and S. Patil, "Application of value engineering technique to a residential building - case study," International Journal of Innovative Research in Advanced Engineering, vol. 1, no. 12, pp. 115-118, 2014.

[41] A. Japaar, N. A. Maznan, and M. Zawawi, "Implementation of value management in public projects," Procedia Social and Behavioural Sciences, vol. 68, pp. 77-86, 2012.

[42] M.-y. Leung, "Reasons for applying VM - an international comparison," in Proceedings of the 49th Annual Conference of SAVE International, pp. 40-45, Detroit, United States, 29 June - 2 July 2009.

[43] R. Yanita and K. Mochtar, "Legal aspect of value engineering implementation in Jakarta (Indonesia) construction projects," International Journal of Construction Management, vol. 21, no. 2, pp. 131-139, 2018.

[44] V. Shahhosseini, M. R. Afshar, and O. Amiri, "Value engineering practices in infrastructure projects: a case study of ilam gas refinery's water transmission system at reno mountain, Iran," International Journal of Construction Management, vol. 18, no. 5, pp. 351-363, 2018. 
[45] X. Li, C. Wang, and A. Alshwal, "Case study on BIM and value engineering integration for cost control," Advances in Civil Engineering, vol. 2021, no. 8, pp. 1-13, Article ID 8849303, 2021.

[46] A. H. Thara and E. E. Elbeltagi, "Integrating building information modelling with value engineering to facilitate the selection of building design alternatives considering sustainability," International Journal of Construction Management, pp. 1-16, 2021.

[47] W. Y. El-Nashar and A. H. Elyamany, "Value engineering for canal tail irrigation water problem," Ain Shams Engineering Journal, vol. 9, no. 4, pp. 1989-1997, 2018.

[48] S. Azis, A. Nurdin, and E. H. Putranto, "Application of value engineering on the construction of tertiary irrigation channel," Research Journal of Applied Sciences, vol. 11, no. 11, pp. 1328-1333, 2016.

[49] L. Brais and J. J. Plant, "Delivering value on the port of miami tunnel project," Value World, vol. 36, no. 2, pp. 21-29, 2013. 